\title{
Association between adiposity indicators, metabolic parameters and inflammatory markers in a sample of female adolescents
}

Priscilla Rizental Coutinho', Neiva Leite ${ }^{2}$, Wendell Arthur Lopes ${ }^{3,4}$, Larissa Rosa da Silva², Cássio M. Consentino², Cristiane T. Araújo², Frederico B. Moraes Jr. ${ }^{2}$, Incare C. de Jesus'2, Cláudia Regina Cavaglieri³ ${ }^{3}$ Rosana Bento Radominski ${ }^{1,5}$

\begin{abstract}
Objective: The aim of this study was to investigate the association between total and abdominal adiposity with metabolic parameters and inflammatory markers, in female adolescents. Subjects and methods: The sample consisted of 53 adolescents aged 13 to 17 years from a public school in Curitiba, Brazil. The adiposity indicators studied were body mass index (BMI), waist circumference (WC), trunk fat mass (TKFM), total fat mass (TFM) and body fat percentage (BF\%) measured by dual-energy $\mathrm{X}$-ray absorptiometry. The metabolic and inflammatory parameters studied were systolic blood pressure (SBP), diastolic blood pressure (DBP), glucose, insulin, homeostasis model assessment index for insulin resistance (HOMA-IR), lipids, C-reactive protein (CRP), interleukin-6 (IL-6), tumor necrosis factor alpha (TNF- $\alpha$ ), leptin, adiponectin and resistin. Results: Eighty percent of WC variation, 87\% of TKFM andTFM, and $73 \%$ of $B F \%$ were predicted by $B M I$ variation. There was a significant positive correlation between all indicators of adiposity with SBP, DBP, insulin, HOMA-IR, CRP and leptin. Triglycerides were positively correlated with $\mathrm{BMI}$ and $\mathrm{WC}$, and adiponectin correlated negatively with BMI.TNF- $\alpha$, IL-6, glucose, total cholesterol, and high- and low-density lipoprotein cholesterol did not correlate to the studied variables. Conclusion: BMI showed a significant association with most of the parameters studied, and WC was slightly better than BMI to predict insulin resistance in this specific population. Arch Endocrinol Metab. 2015;59(4):325-34
\end{abstract}

Keywords

Adolescents; obesity; abdominal adiposity; cardiovascular risk
1 Programa de Pós-Graduação em Segurança Alimentar e Nutricional, Setor de Ciências da Saúde, Universidade Federal do Paraná (UFPR), Curitiba, PR, Brazil ${ }^{2}$ Núcleo de Pesquisa em Qualidade de Vida, Departamento de Educação Física, UFPR, Curitiba, PR, Brazil

${ }^{3}$ Faculdade de Educação Física, Universidade Estadual de Campinas (Unicamp), Campinas, SP, Brazil ${ }^{4}$ Departamento de Educação Física, Universidade Estadual de Maringá (UEM), Ivaiporã, PR, Brazil ${ }^{5}$ Serviço de Endocrinologia e Metabologia, UFPR, Serviço de Endocrinologia e Metabologia (SEMPR), Curitiba, PR, Brazil

\section{Correspondence to:}

Rosana Bento Radominski

Av. Prefeito Lothário Meissner, 632

80210-170 - Curitiba, PR, Brazil

rbr@ufpr.br

Received on May/11/2015

Accepted on May/25/2015

DOI: 10.1590/2359-3997000000070

\section{INTRODUCTION}

$\mathrm{O}$ besity in children and adolescents has increased significantly in recent decades, resulting in the development of chronic diseases and metabolic syndrome during adulthood (1). Abdominal or central adiposity is a risk factor for diabetes and cardiovascular disease in adults, regardless of the degree of obesity. In children and adolescents, the impact of body fat distribution in obesity complications is uncertain (2).

Obesity induces adipocyte dysfunction, with secretion of adipokines and macrophage activation leading to inflammatory cytokine production, which results in a cascade of reactions that influence metabolic parameters, atherogenic processes and insulin sensitivity (3).
Body mass index (BMI) is used for the diagnosis of obesity in adolescents, although it does not assess the distribution of body fat (4). Studies have suggested that the evaluation of waist circumference (WC) would better detect cardiovascular risk, metabolic disorders and insulin resistance in youth (5). However, other researchers have reported divergent results $(6)$ and, to date, there is no consensus on the usefulness of central obesity indicators as tools for detecting cardiometabolic risk factors in adolescents.

Computed tomography and magnetic resonance imaging are the gold standard methods in assessing the distribution of abdominal fat, but its high cost and radiation are limiting factors. For body composition analysis, the dual-energy $\mathrm{x}$-ray absorptiometry (DXA) is a 
simple and low-risk method that evaluates the regional and total fat distribution with very good correlation with other radiological exams (7).

The aim of this study was to evaluate, in a sample of female adolescents, the association of different indicators of adiposity with metabolic parameters and inflammatory markers, and to elucidate which adiposity measures identify individuals at risk of obesity complications.

\section{SUBJECTS AND METHODS}

\section{Subjects}

This study is cross-sectional and comprised of adolescent girls, aged 13 to 17 years, from the $8^{\text {th }}$ grade of elementary school to the $3^{\text {th }}$ grade of high school, who studied in a public school in the city of Curitiba/ Paraná. The volunteers were recruited from April to October 2013 and were part of a previous longitudinal study. The girls should be in the final stages of puberty, to be included in the study (Tanner stages IV and $\mathrm{V})(8)$. The exclusion criteria were the presence of chronic diseases, such as diabetes, non-controlled hypothyroidism, endocrine diseases, infection and/or the use of medications that promoted changes in adiposity, metabolic or inflammatory parameters. The exclusion criteria were based on clinical history and, in uncertain cases, complementary exams were performed.

The volunteers underwent a medical consultation with complete anamneses and physical examinations, which included anthropometric measurements, checking vital data and sexual maturation analysis as proposed by Tanner (8). All tests were carried out with a maximal interval of one week between them.

\section{Body composition and anthropometry}

Weight was measured with the subjects standing and wearing light clothes and barefoot, using a calibrated mechanical anthropometric scale (Filizola, São Paulo, Brazil), with precision of $0.1 \mathrm{~kg}$ and maximum capacity of $150 \mathrm{~kg}$. Height was measured by a wall-mounted stadiometer (Tonelli, Criciúma, Brazil), with variation of 0.1 $\mathrm{cm}$ to $220 \mathrm{~cm}$ range. BMI was calculated as weight divided by height squared $\left(\mathrm{kg} / \mathrm{cm}^{2}\right)$. BMI z-score was calculated and classified according to criteria defined by the World Health Organization for sex and age (9). Taking into consideration the BMI curve for their ages, subjects were considered: eutrophic, when BMI was between the score $\geq \mathrm{z}-2$ and $<\mathrm{z}+\mathrm{l}$; overweight, when BMI was between score $\geq \mathrm{z}+\mathrm{l}$ and $<\mathrm{z}+2$; and obese when BMI was $\geq \mathrm{z}+2$.

WC was measured midpoint between the last ribs and the iliac crests with an inelastic measuring tape with precision of $0.1 \mathrm{~cm}$, and with the participant having overnight fasted and in a standing position (10). The measurement was performed in triplicate by a single trained professional. The average of the three measurements was calculated and converted to $\mathrm{z}$-scores adjusted for age, according to data from the National Health and Nutrition Examination Surveys (11).

Body composition was assessed by Lunar Prodigy Primo DXA (GE Medical Systems Lunar, Madison, Wisconsin, USA). The examinations were performed by a single trained professional, with intraobserver coefficient of variation of $0.1 \%$ for total mass, $2.4 \%$ for total fat mass (TFM), 3.06\% for trunk fat mass (TKFM) and $1.64 \%$ for body fat percentage $(\mathrm{BF} \%)$. The subjects wore appropriate clothing, with no metal parts. Body composition was obtained with subjects in supine position on the exam table. Scanning was carried out from the upper cranial region to the ankle region. TFM and TKFM were determined with approximation to $\mathrm{l} g$ and are described in $\mathrm{kg}$. BF\% was determined by TFM/total body mass ratio. TKFM was measured in the area bordered by a horizontal line below the chin, vertical lines lateral to the ribs, and oblique lines passing through the femoral necks. For the reconstruction of the image of subjacent tissues and quantification of bone mineral content, TFM and free-fat mass, the enCORE 2008 (version 12.30) software (GE Medical Systems, Madison, Wisconsin, USA) was used.

\section{Blood pressure and laboratory analysis}

Blood pressure was measured by a calibrated sphygmomanometer (BD, Germany) with the subject seated after five minutes of rest. The measurement was carried out on the left upper arm, and the cuff was selected in order to cover two-thirds of the arm perimeter. The presence of sound in the brachial artery was used to identify the systolic blood pressure (SBP), and its disappearance was used to identify the diastolic blood pressure (DBP). After the first measurement, the air of the cuff was totally released and, after two minutes, a new measurement was carried out. The average of the two measurements was obtained and converted into z-score for height and age, according to guidelines of The Fourth Report on the Diagnosis, Evaluation and Treatment of High Blood Pressure in Children and Adolescents of the National High Blood Pressure Education Program (12). 
Serum and plasma blood samples $(20 \mathrm{~mL})$ were obtained from the antecubital vein and collected into vacutainer tubes containing EDTA anticoagulant (Becton Dickinson Ltd., Oxford, UK) by a trained phlebotomist. The samples were collected in the morning (07:00-09:00) after a 12-h overnight fast. All samples were collected, processed, divided into serum or plasma aliquots and stored at $-80{ }^{\circ} \mathrm{C}$ for subsequent analysis. Serum samples were used for inflammatory and lipids analysis and plasma samples were used for insulin and glucose analysis.

Total cholesterol, triglycerides and high-density lipoprotein (HDL) levels were analyzed using a commercial kit. Low-density lipoprotein (LDL) was calculated using the Friedewald equation (13). Blood glucose levels were determined by the enzymatic method and insulin was measured by the chemiluminescence immunoassay technique by automated equipment. Insulin resistance was estimated by the homeostasis model assessment (HOMA-IR) described by Matthews and cols. (14).

Serum concentrations of C-reactive protein (CRP), tumor necrosis factor alpha (TNF- $\alpha$ ), interleukin-6 (IL$6)$, resistin, leptin and adiponectin were determined by enzyme-linked immunosorbent assay (ELISA), following the specifications of the manufacturer (Quantikine High Sensitivity Kit, R\&D Systems, Minneapolis, MN, USA). The intra-assay and inter-assay coefficients and sensitivity were as follows: $7.4 \%, 6.5 \%$ and $0.039 \mathrm{pg} /$ $\mathrm{mL}$ for IL-6; 3.1\%, $7.2 \%$ and $0.106 \mathrm{pg} / \mathrm{mL}$ for TNF- $\alpha$; $3.8 \%, 6.0 \%$ and $0.010 \mathrm{ng} / \mathrm{mL}$ for CRP; $3.0 \%, 3.5 \%$ and $7.8 \mathrm{pg} / \mathrm{mL}$ for leptin; $2.8 \%, 5.9 \%$ and $0.246 \mathrm{ng} / \mathrm{mL}$ for adiponectin; $3.8 \%, 7.8 \%$ and $0.026 \mathrm{ng} / \mathrm{mL}$ for resistin.

\section{Assessment of adiposity and metabolic parameters}

The indicators of total adiposity considered in this study were BMI, TFM $(\mathrm{kg})$ and BF\% and the indicators of central adiposity were WC and TKFM. The metabolic parameters included in the analyzes were SBP, DBP, total cholesterol, HDL, LDL, triglycerides, glucose, insulin and HOMA-IR, and the inflammatory parameters were CRP, IL-6, TNF- $\alpha$, leptin, resistin and adiponectin.

This research was approved by the Ethics Committee of the Clinical Hospital of the Federal University of Parana (Protocol number $2460.067 / 2011$ ).

\section{Statistical analysis}

The data are presented as means and standard deviation or median and interquartile range, according to the normality assumption assessed by the Shapiro-Wilk test. The variables DBP, insulin, HOMA-IR, triglycerides, CRP, TNF- $\alpha$, IL- 6 , leptin, resistin and adiponectin were transformed into logarithms for linear regression analysis, as they do not have a normal distribution. Pearson correlation and multiple linear regression were used for the analysis of central and total obesity indicators in relation to the studied variables. Data were analyzed using IBM SPSS Statistics for Windows, Version 19.0. (Armonk, NY: IBM Corp.), with $p \leq 0.05$ considered significant.

\section{RESULTS}

Of the 341 recruited girls, 55 volunteered of which 53 met the inclusion criteria with two teenagers excluded owing to pubertal stage. Mean age, weight and height were $14.66 \pm 1.10$ years, $70.24 \pm 14.23 \mathrm{~kg}$ and 162.40 $\pm 5.70 \mathrm{~cm}$, respectively. Twenty-one girls were obese (39.6\%), 17 overweight (32.1\%) and 15 were normal weight $(28.3 \%)$. The characteristics of the study population are shown in table 1 .

Table 1. Characteristics of the study participants

\begin{tabular}{|c|c|c|c|}
\hline Parameter & $n=53$ & Minimum & Maximum \\
\hline BMl-z & $1.7(0.6-2.3)^{b}$ & -0.7 & 3.0 \\
\hline WC-Z & $0.2 \pm 0.8^{\mathrm{a}}$ & -1.4 & 2.2 \\
\hline TFM (kg) & $28.6 \pm 10.0^{a}$ & 12.3 & 52.9 \\
\hline TKFM (kg) & $14.0 \pm 5.6^{\mathrm{a}}$ & 5.2 & 27.3 \\
\hline $\mathrm{BF} \%$ & $39.8 \pm 7.1^{\mathrm{a}}$ & 23.8 & 56.0 \\
\hline SBP-Z & $0.78 \pm 9.7^{a}$ & -2.9 & 1.0 \\
\hline DBP-z & $-1.17 \pm 0.7^{a}$ & -1.5 & 2.2 \\
\hline Glucose (mg/dL) & $87.4 \pm 8.1^{\mathrm{a}}$ & 70.8 & 111.0 \\
\hline Insulin (mU/mL) & $12.0(9.9-18.7)^{b}$ & 5.2 & 60.6 \\
\hline HOMA-IR & $2.5(2.0-4.1)^{b}$ & 1.0 & 13.9 \\
\hline Total cholesterol (mg/dL) & $160.8 \pm 29.2^{\mathrm{a}}$ & 100.3 & 217.4 \\
\hline HDL (mg/dL) & $57.3 \pm 10.7^{a}$ & 35.5 & 89.8 \\
\hline LDL (mg/dL) & $82.8 \pm 21.8^{\mathrm{a}}$ & 43.9 & 141.5 \\
\hline $\mathrm{TG}(\mathrm{mg} / \mathrm{dL})$ & $83.9(70.0-120.2)^{b}$ & 41.0 & 403.7 \\
\hline $\mathrm{CRP}$ (ng/mL) & $1.4(0.5-4.7)^{b}$ & 0.0 & 11.0 \\
\hline TNF- $\alpha(p g / m L)$ & $1.7(1.2-2.4)^{\mathrm{b}}$ & 0.6 & 14.8 \\
\hline IL-6 (pg/mL) & $1.2(0.9-2.0)^{b}$ & 0.5 & 8.5 \\
\hline Resistin (ng/mL) & $6.7(5.2-8.7)^{b}$ & 2.4 & 19.0 \\
\hline Adiponectin (ng/mL) & $5.8(4.9-9.3)^{b}$ & 0.8 & 26.1 \\
\hline Leptin (pg/mL) & $40.4(25.9-59.5)^{b}$ & 8.6 & 104.4 \\
\hline
\end{tabular}

a: Data in means \pm standard deviation. b: Data in median and inter-quartile range.

$\mathrm{BF} \%$ : body fat percentage; BMI-z: body mass index z-score; DBP-z: diastolic blood pressure z-score; HDL: HDL cholesterol; LDL: LDL cholesterol; SBP-z: sistolic blood pressure z-score; TFM: total fat mass; TG: triglycerides; TKFM: trunk fat mass. WC-z: waist circumference z-score. 


\section{Adiposity indicators}

There was a significant positive correlation between all the adiposity indicators studied. TFM was strongly associated with BMI $(\mathrm{r}=0.934)$ and $\mathrm{BF} \%(\mathrm{r}=0.854)$, and TKFM showed excellent correlation with WC $(\mathrm{r}=$ $0.912)$, demonstrating that the anthropometric measures were strongly related according to the gold standard measurements obtained by DXA (data not available in table).

Approximately $80 \%$ of the variation in WC, $87 \%$ of both TKFM and TFM, and $73 \%$ of the BF\% could be predicted by the variation in BMI (Figure 1). The WC varied $83 \%$ depending on the TKFM, $80 \%$ as a function of TFM and $60 \%$ in relation to $\mathrm{BF} \%$ (Figure 2).
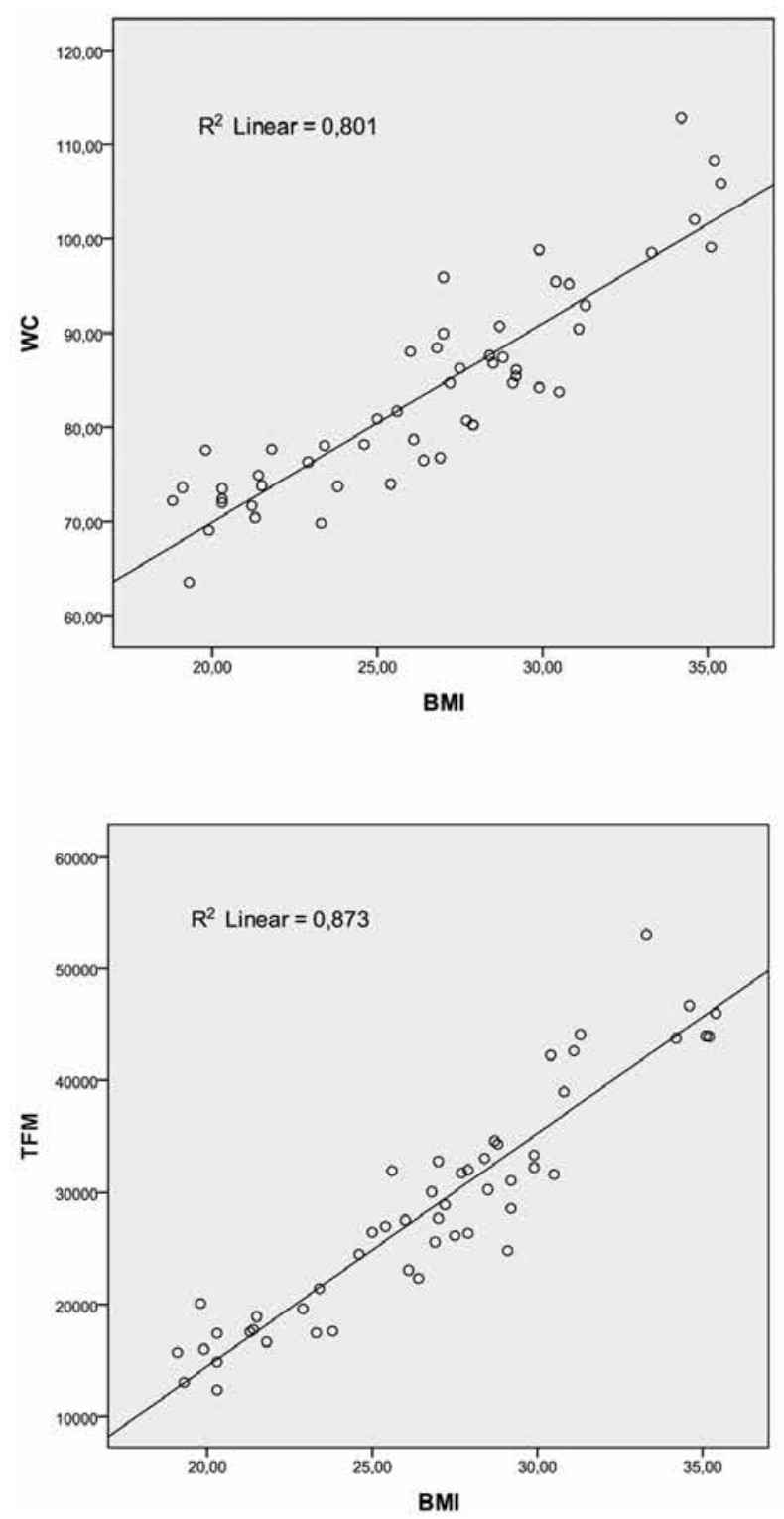

Figure 1. Scatter diagram of body fat measurements in relation to BMI.

\section{Metabolic parameters}

All adiposity indicators demonstrated a significant positive association with SBP, DBP, insulin and HOMA-IR index. Twenty-three percent of the SBP variation was explained by TFM, followed by BF\%, TKFM and BMI. The explanatory power of these indicators was similar and higher than with the WC. Twenty-seven percent of DBP variation was due to TFM, followed by BMI, WC and TKFM with almost identical associations (Table 2).

For insulin values and HOMA-IR index, a greater effect can be observed with WC (38\% for both) compared with BMI (34\% and 33\%, respectively) and other measures of adiposity. The WC sensitivity for detection of girls with HOMA-IR $\geq 2.70$ was $88 \%$ with a specificity of $60.7 \%$, and for BMI the sensitivity was $76 \%$ and specificity of $71.4 \%$.
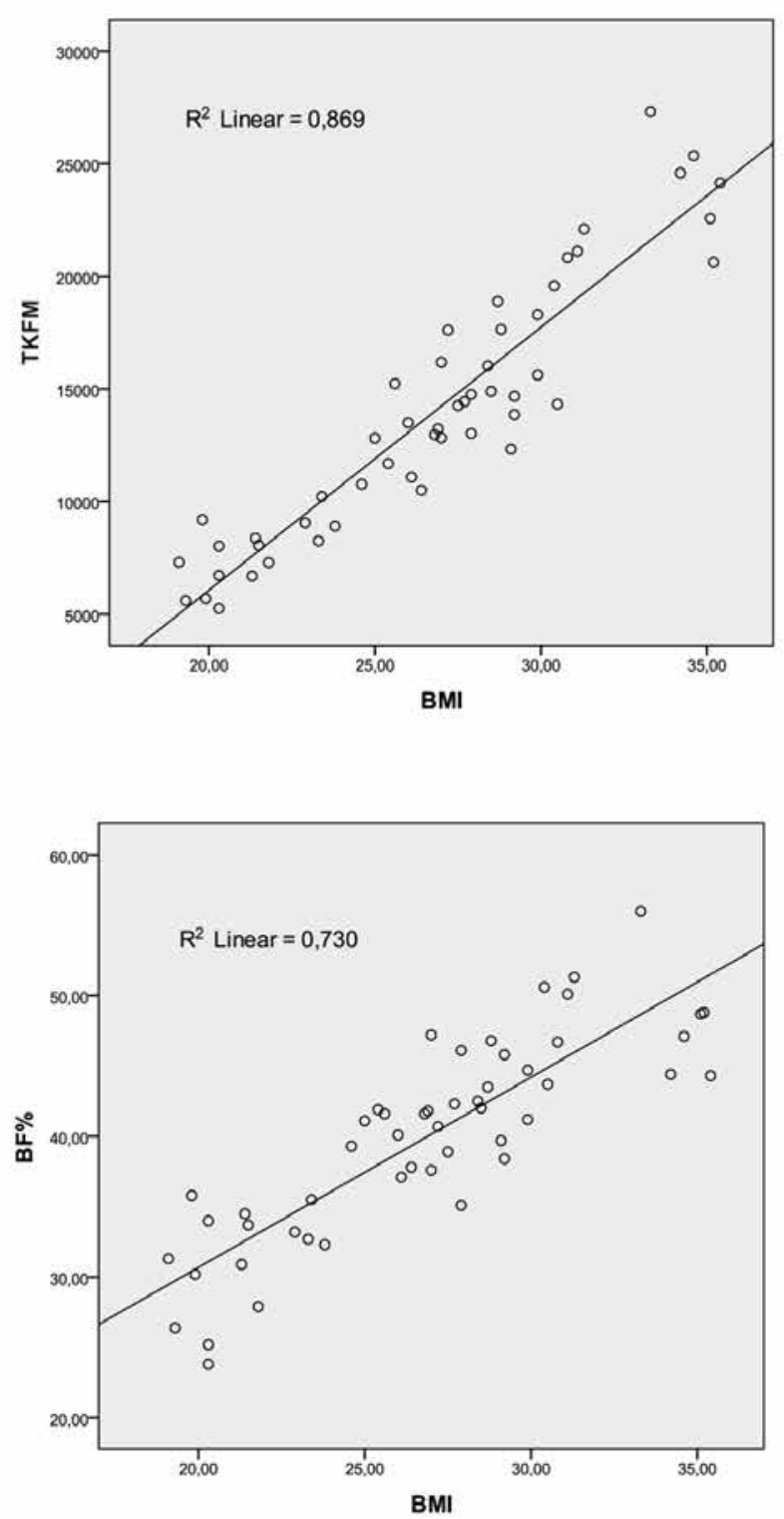

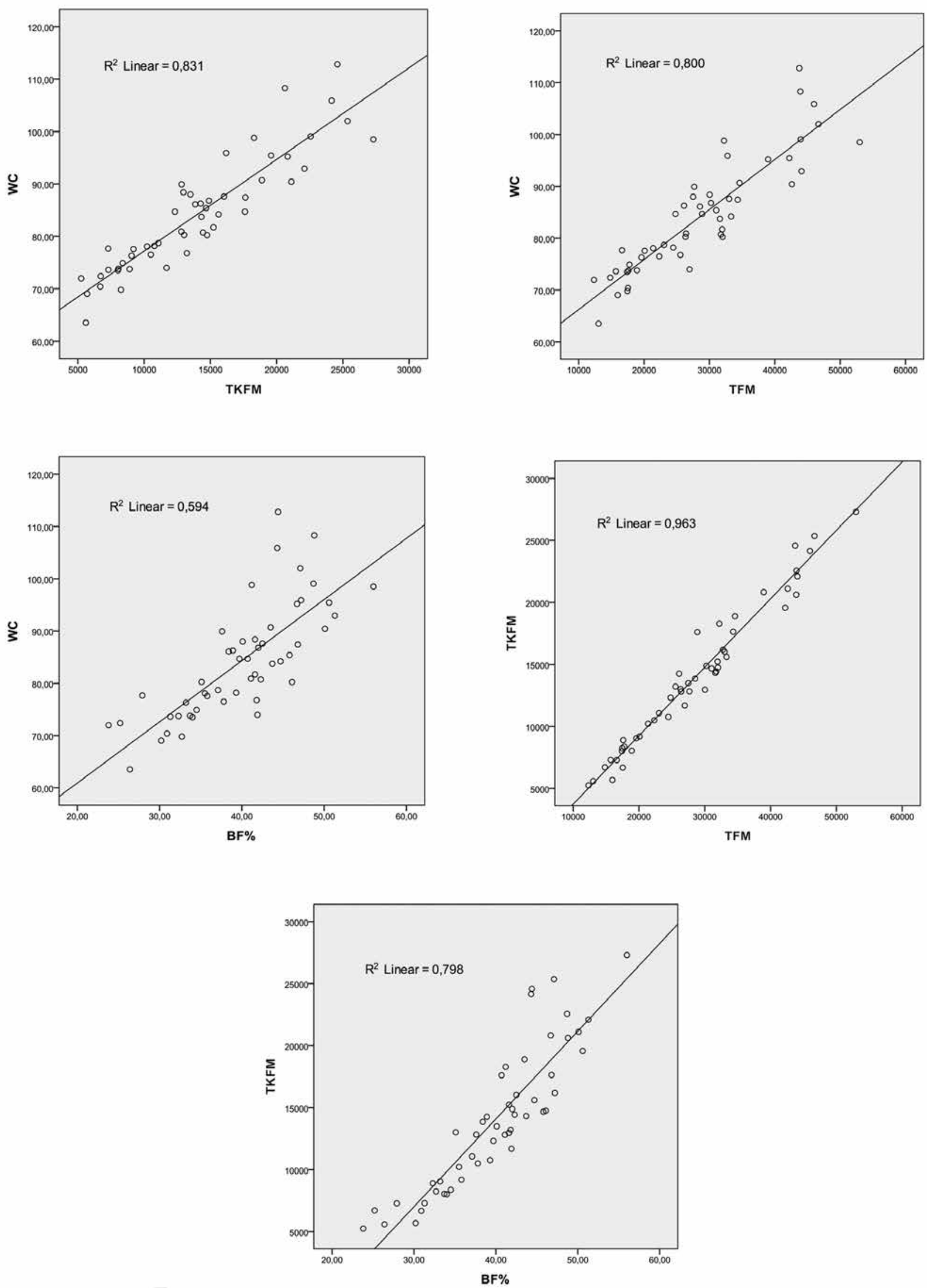

Figure 2. Scatter diagram of central adiposity. 
Table 2. Linear regression coeficients $(\beta)$ e $\mathrm{r}^{2}$ for central and total adiposity measures with metabolic parameters

\begin{tabular}{|c|c|c|c|c|c|c|}
\hline & & BMI & WC & TKFM & TFM & BF\% \\
\hline & $\beta$ & $0.44^{\star *}$ & $0.42^{\star \star}$ & $0.45^{\star \star}$ & $0.48^{\star \star}$ & $0.47^{\star \star}$ \\
\hline \multirow[t]{2}{*}{ SBP } & $r^{2}$ & 0.20 & 0.18 & 0.21 & 0.23 & 0.22 \\
\hline & $\beta$ & $0.51^{\star *}$ & $0.51^{\star *}$ & $0.50^{\star *}$ & $0.52^{\star \star}$ & $0.47^{\star \star}$ \\
\hline \multirow[t]{2}{*}{ DBP } & $r^{2}$ & 0.26 & 0.26 & 0.25 & 0.27 & 0.22 \\
\hline & $\beta$ & 0.24 & 0.26 & 0.19 & 0.15 & 0.09 \\
\hline \multirow[t]{2}{*}{ Glucose } & $r^{2}$ & 0.06 & 0.07 & 0.03 & 0.02 & 0.00 \\
\hline & $\beta$ & $0.58^{* *}$ & $0.61^{* *}$ & $0.53^{\star \star}$ & $0.51^{\star *}$ & $0.38^{\star \star}$ \\
\hline \multirow[t]{2}{*}{ Insulin } & $r^{2}$ & 0.34 & 0.38 & 0.29 & 0.26 & 0.15 \\
\hline & $\beta$ & $0.57^{\star \star}$ & $0.61^{\star *}$ & $0.53^{\star \star}$ & $0.50^{\star \star}$ & $0.36^{\star \star}$ \\
\hline \multirow[t]{2}{*}{ HOMA-IR } & $r^{2}$ & 0.33 & 0.38 & 0.29 & 0.25 & 0.13 \\
\hline & $\beta$ & 0.20 & 0.22 & 0.17 & 0.21 & 0.17 \\
\hline \multirow[t]{2}{*}{ TC } & $r^{2}$ & 0.04 & 0.05 & 0.03 & 0.04 & 0.03 \\
\hline & $\beta$ & 0.05 & 0.07 & 0.06 & 0.10 & 0.12 \\
\hline \multirow[t]{2}{*}{ LDL } & $r^{2}$ & 0.00 & 0.00 & 0.00 & 0.01 & 0.01 \\
\hline & $\beta$ & 0.05 & 0.01 & 0.03 & 0.10 & 0.07 \\
\hline \multirow[t]{2}{*}{ HDL } & $r^{2}$ & 0.00 & 0.00 & 0.00 & 0.01 & 0.00 \\
\hline & $\beta$ & $0.31^{\star}$ & $0.34^{*}$ & 0.26 & 0.24 & 0.15 \\
\hline TG & $r^{2}$ & 0.10 & 0.12 & 0.07 & 0.06 & 0.02 \\
\hline \multirow[t]{2}{*}{ CRP } & $\beta$ & $0.38^{\star *}$ & $0.41^{\star *}$ & $0.40^{\star \star}$ & $0.43^{\star \star}$ & $0.44^{\star \star}$ \\
\hline & $r^{2}$ & 0.15 & 0.17 & 0.16 & 0.19 & 0.20 \\
\hline \multirow[t]{2}{*}{ IL-6 } & $\beta$ & 0.11 & 0.18 & 0.07 & 0.12 & 0.13 \\
\hline & $r^{2}$ & 0.01 & 0.03 & 0.00 & 0.02 & 0.02 \\
\hline \multirow[t]{2}{*}{ TNF- $\alpha$} & $\beta$ & 0.22 & 0.25 & 0.24 & 0.23 & 0.21 \\
\hline & $r^{2}$ & 0.05 & 0.06 & 0.06 & 0.05 & 0.04 \\
\hline \multirow[t]{2}{*}{ Resistin } & $\beta$ & 0.25 & 0.22 & 0.22 & 0.21 & $0.29^{\star}$ \\
\hline & $r^{2}$ & 0.06 & 0.05 & 0.05 & 0.04 & 0.08 \\
\hline \multirow[t]{2}{*}{ Leptin } & $\beta$ & $0.78^{\star *}$ & $0.70^{\star \star}$ & $0.74^{\star \star}$ & $0.78^{\star \star}$ & $0.76^{\star \star}$ \\
\hline & $r^{2}$ & 0.61 & 0.49 & 0.55 & 0.61 & 0.58 \\
\hline \multirow[t]{2}{*}{ Adiponectin } & $\beta$ & $-0.28^{\star}$ & -0.19 & -0.22 & -0.15 & -0.13 \\
\hline & $r^{2}$ & 0.08 & 0.04 & 0.05 & 0.02 & 0.02 \\
\hline
\end{tabular}

${ }^{\star} p<0.05 ;{ }^{\star \star} p<0.01$

BF\%: body fat percentage; BMI-z: body mass index z-score; DBP-z: diastolic blood pressure z-score; HDL: HDL cholesterol; HOMA-IR: Homeostasis Model Assessment; LDL: LDL cholesterol; SBP-z: sistolic blood pressure z-score; TC: total cholesterol; TFM: total fat mass; TG: triglycerides; TKFM: trunk fat mass. WC-z: waist circumference z-score.

Glucose, total cholesterol, HDL and LDL were not associated with the adiposity indicators studied. Triglycerides varied according to the BMI and WC similarly.

\section{Inflammatory markers}

All adiposity indicators demonstrated a significant positive association with the CRP and leptin levels. The CRP was mostly influenced by the BF\%, TFM and WC, and leptin varied $61 \%$ based on BMI and TFM. Resistin correlated positively only with the $\mathrm{BF} \%$, and adiponectin correlated negatively with BMI. IL-6 and TNF- $\alpha$ were not associated with the adiposity indicators studied.

\section{Metabolic parameters and inflammatory markers}

When analyzing inflammatory markers in relation to metabolic parameters, we observed an association of CRP to insulin and to HOMA-IR index, and also of leptin with SBP, DBP, insulin and HOMA-IR. Adiponectin was inversely correlated with blood glucose, insulin, HOMA-IR and triglycerides and TNF- $\alpha$ showed a negative association with HDL (Table 3 ).

\section{DISCUSSION}

Excess weight can begin in childhood and researchers have discussed how to identify, in this age group, those individuals who are at risk of obesity complications. 
Some authors argue that the pattern of distribution of fat, especially abdominal fat, would be effective in predicting risk (15). However, the data for children and adolescents are not clear and there are no established cutoff points for the pediatric population. BMI, despite its limitations on assessment of body fat distribution and the distinction between lean mass and fat mass, is an indicator of adiposity validated for the pediatric population (16). Given the controversy regarding the different methods of assessing adiposity in children and adolescents and their clinical implications, more studies are needed to identify the applicability of these parameters in this specific population.

In this study, adiposity measurements were strongly correlated with each other, and adolescents with higher BMI also presented higher WC, TKFM, TFM and BF\% values, indicating that in the population analyzed, BMI properly identified adiposity. Studies evaluating the distribution of fat in adolescents, with similar results of this study, found a strong association between BMI and WC $(\mathrm{r}=0.88-0.91)(17,18)$ and between TFM and BMI $(r=0.84-0.97)(19,20)$. Especially in girls, BMI has been a good indicator of adiposity, because in females a greater fat deposition occurs during the pubertal period (21).

In the present study, both BMI and WC explain similar variations in TKFM, demonstrating that these two anthropometric parameters shared similar influence in the estimation of abdominal adiposity. WC measurement seems to be a reflection of the total adiposity in this population, which is different from that observed in adults. Its measure would bring no further information, since BMI and WC assess the same thing in this particular group.
The relationship between direct and indirect measures of central and total body fat has been widely discussed. The Avon Longitudinal Study of Parents and Children (ALSPAC) demonstrated strong and stable correlation between BMI and WC in children aged 9 to 11 years $(\mathrm{r}=0.91$ to 0.92$)$, with attenuation at $13(\mathrm{r}=$ $0.88)$ and 15 years of age $(r=0.84)$. The same pattern has been observed with TKFM and TFM measured by DXA (22). Perhaps these results indicate that with increasing age there is a reduction of the influence of BMI on central adiposity, but the question is to know at what age the abdominal fat will became clinically important.

The blood pressure levels have had similar correlation with all the adiposity indicators, showing that any of them can indicate individuals at risk for hypertension. Some authors suggested that blood pressure appears to be more dependent on total body fat rather than fat distribution in this age group. Adolescents and children with higher levels of blood pressure, even within normal limits, tend to progress over a lifetime showing higher incidence of hypertension in adulthood (23-25). A national study of 1716 volunteers aged 10-16 years has shown that obesity detected by BMI, adjusted for sex, age and skin color increased by $27 \%$ the chance of a teenager presenting with hypertension; WC, despite its association with blood pressure, lost its effect after adjustment for BMI (26).

In this study, WC showed a close association with insulin levels, HOMA-IR and triglycerides, with minimal difference in relation to BMI. These two indicators, WC and BMI, were better than the measure of adiposity by DXA for these parameters. Possibly the highest concentration of intra-abdominal fat, responsible for such changes, is best assessed by measuring WC.

Table 3. Correlations between metabolic parameters and inflammatory markers

\begin{tabular}{lcccccc}
\hline & CRP & IL-6 & TNF- $\alpha$ & Resistin & Leptin & Adiponectin \\
\hline SBP & 0.128 & -0.039 & 0.052 & 0.266 & $0.296^{\star}$ & -0.148 \\
DBP & 0.056 & -0.044 & 0.085 & 0.022 & $0.379^{\star}$ & -0.140 \\
Glucose & 0.139 & -0.117 & -0.092 & -0.153 & 0.053 & $-0.292^{\star}$ \\
Insulin & $0.317^{*}$ & 0.091 & 0.162 & -0.156 & $0.387^{\star \star}$ & $-0.362^{\star *}$ \\
HOMA-IR & $0.326^{\star}$ & 0.076 & 0.118 & -0.183 & $0.358^{\star *}$ & $-0.377^{\star *}$ \\
TC & 0.114 & -0.133 & -0.006 & -0.020 & 0.206 & 0.046 \\
HDL & 0.108 & -0.089 & $-0.279^{\star}$ & 0.010 & 0.051 & 0.257 \\
LDL & -0.014 & -0.130 & 0.081 & 0.060 & 0.142 & 0.122 \\
TG & 0.131 & 0.000 & 0.063 & -0.197 & & 0.179 \\
\hline
\end{tabular}

Pearson's correlation * $p<0.05 ;{ }^{* *} p<0.01$.

DBP-z: diastolic blood pressure z-score; HDL: HDL cholesterol; LDL: LDL cholesterol; TC: total cholesterol; TG: triglycerides; SBP-z: sistolic blood pressure z-score. 
Previous studies have shown that WC is a strong predictor of insulin resistance in adolescents, regardless of BMI, BF\% and TFM (27-29). However, in most of these studies, the samples were small and the age groups varied considerably (8-17 years) making it difficult to understand any real association or reflection of change in body composition.

Blüher and cols. (30) in a prospective study that evaluated the correlation between BMI, WC and TFM, as measured by DXA, for cardiovascular risk factors in 5235 children aged $9-12$ years and 15 and 16 years, found a greater association of BMI with insulin and HOMA-IR, and WC with lipids. The differences in correlation coefficients between BMI and WC were minimal, and the authors concluded that the addition of WC measurement to BMI is of little benefit, and BMI alone would be enough to estimate cardiovascular risk in adolescents.

No association was found in our study between the adiposity indicators and total cholesterol, HDL and LDL, perhaps because the small number of participants may have limited these associations. This interdependence has been demonstrated in epidemiological studies in expressive samples (31). Another factor, which may have influenced the results in our study, was that analysis of food cholesterol intake had not been performed.

Inflammatory markers along with the assessment of adiposity may contribute in identifying those with a higher cardiometabolic risk, in which case the therapeutic efforts should be more intensive. The CRP is a well-established marker of cardiovascular risk and studies in adults have shown the influence of obesity, especially central fat accumulation, as an important determinant of this parameter (32). In the present study, CRP was associated mainly with TFM and BF\% despite a minimal difference for the other indicators of adiposity. Other authors have reported an association of CRP with BMI and the waist-hip ratio (33). CRP was also associated with insulin and HOMA-IR values, similar to that described in the literature (34) indicating that the analysis of this cardiovascular risk marker can help to detect individuals with a higher tendency for insulin resistance independently of adiposity.

TNF- $\alpha$ and IL- 6 are pro-inflammatory cytokines related to a number of pathophysiological processes, including insulin resistance, energy homeostasis and body weight. Similarly to other reports $(35,36)$, we did not find an association between TNF- $\alpha$ and IL- 6 with the adiposity indicators. The production of these cytokines is guided mainly by visceral adipose tissue, which is still scarce in the age group of our study cohort, and it is possible that this inflammatory process is still not present at this time (37). Also, studies in rodents show that triglycerides and free fatty acids exert influence on TNF- $\alpha$ production and recombinant HDL administration has a reducing effect on the expression of this cytokine. This may explain the negative association of TNF- $\alpha$ with HDL found in our study $(38,39)$.

Leptin presents a linear association with total body fat, especially with subcutaneous adipose tissue (40). In the present study, leptin concentration varied in equal proportion to TFM and BMI and was associated with all metabolic parameters related to increased adiposity (SBP, DBP, insulin and HOMA-IR).

Adiponectin, in turn, is associated more specifically with the visceral compartment and reduces proportionately to central fat accumulation, acting as a risk marker for metabolic syndrome (41). In our study, however, adiponectin was negatively associated with BMI and no association was found with central adiposity measurements.

Glucose, insulin, HOMA-IR and triglycerides were negatively correlated with adiponectin, corroborating with authors who have reported that the presence of insulin resistance is associated with lower adiponectin values and higher levels of triglycerides, intravisceral and intramyocellular fat (42). Adiponectin acts through intracellular pathways promoting activation of glucose transporters, fatty acid oxidation in muscle and inhibition of gluconeogenesis resulting in decreased blood glucose and insulin levels. These mechanisms may explain our findings of lower adiponectin levels associated with higher levels of glucose, insulin and HOMA-IR (43).

Resistin was associated only with the $\mathrm{BF} \%$ in our analysis, and its relationship with the distribution of fat, BMI and body fat mass is controversial in the literature (44). What is postulated is that circulating resistin levels tend to increase with age, probably reflecting an increase in body fat content as obese subjects tend to have higher resistin levels compared with lean subjects, but this process is not uniform and when resistin is elevated seems to produce a deleterious effect on angiogenesis with increased cardiovascular risk.

This study has some limitations. The first is that it was done with a voluntary sample selected by convenience, which does not represent an unbiased population of this age group. Second, because the main study included an intervention with exercise and, therefore, raised greater 
interest in the adolescents who desired to lose weight, the proportion of participants who were overweight was higher than the prevalence of overweight and obesity in the general population. Other limitations were the small number of participants and that there was no direct measurement of intra-abdominal fat, since fat location may influence the inflammatory process of obesity and the cytokines evaluated in this study.

In conclusion, all adiposity indicators studied demonstrated a significant positive association with blood pressure, insulin, HOMA-IR, CRP and leptin. Triglycerides were positively associated with BMI and WC, and adiponectin negatively associated in relation to BMI. IL-6, TNF- $\alpha$, glucose, total cholesterol, HDL and LDL cholesterol were not associated with adiposity indicators.

BMI was the adiposity indicator associated with most of the parameters studied, and it was characterized as an adequate tool to detect individuals in our study at risk for obesity complications. WC measurement was mainly correlated to the presence of insulin resistance, constituting a slightly better instrument for identifying individuals with this condition in this sample.

Few national studies have investigated adiposity indicators compared with DXA, which is the gold standard method for measuring total and regional body fat. This study contributes relevant information to the understanding of obesity and its relation to metabolic parameters and inflammatory markers in the transitional period of adolescence.

Acknowledgements: we are thankful to Fundação Araucária for financial support for this project and to the Centro de Terapias Inovadoras for body composition tests (DXA); to the Exercise Physiology Laboratory at Universidade Estadual de Campinas (Unicamp) for the analysis of the inflammatory markers; and to the Physical Education Department of Universidade Federal do Paraná (UFPR) and their undergraduate and graduate students. The third, fourth, sixth and seventh authors have Conselho Nacional de Desenvolvimento Científico e Tecnológico (CNPq) scholarships, and the second and tenth authors have CNPq productivity grants.

Academic affiliation: this article is part of the master's degree thesis of Priscilla Rizental Coutinho in the Food and Nutrition Safety Program at UFPR.

Disclosure: no potential conflict of interest relevant to this article was reported.

\section{REFERENCES}

1. Instituto Brasileiro de Geografia e Estatística. Pesquisa de Orçamentos Familiares (POF) 2008-2009. Antropometria e estado nutricional de crianças, adolescentes e adultos no Brasil. Rio de Janeiro: IBGE; 2010.

2. Lawlor DA, Benfield L, Logue J, Tilling K, Howe LD, Fraser A, et al. Association between general and central adiposity in childhood, and change in these, with cardiovascular risk factors in adolescence: prospective cohort study. BMJ. 2010;341:c6224.

3. Hermsdorff HH, Zulet MA, Puchau B, Martínez JA. Central adiposity rather than total adiposity measurements are specifically involved in the inflammatory status from healthy young adults. Inflammation. 2011;34(3):161-70.

4. Li C, Ford ES, Mokdad AH, Cook S. Recent trends in waist circumference and waist-height ratio among US children and adolescents. Pediatrics. 2006;118(5):e1390-8.

5. Spolidoro JV, Pitrez Filho ML, Vargas LT, Santana JC, Pitrez E, Hauschild JA, et al. Waist circumference in children and adolescents correlate with metabolic syndrome and fat deposits in young adults. Clin Nutr. 2013;32(1):93-7.

6. Bell L, Hung J, Knuiman M, Divitini M, Beilby J, Hunter M, et al. Body mass index and waist circumference: relationship to cardiometabolic risk factors in children - Busselton Health Study 20052007. J Paediatr Child Health. 2013;49(11):955-62.

7. Goulding A, Taylor RW, Gold E, Lewis-Barned NJ. Regional body fat distribution in relation to pubertal stage: a dual-energy $X$-ray absorptiometry study of New Zealand girls and young women. Am J Clin Nutr. 1996;64(4):546-51.

8. Tanner JN. Growth at adolescence with a general consideration of the effects of hereditary and environmental factors upon growth and maturation from birth to maturity. 2nd ed. Oxford: Blackwell Scientific Publications; 1962.

9. Ministério da Saúde. Secretaria de Atenção à Saúde. Departamento de Atenção Básica. Coordenação-Geral da Política de Alimentação e Nutrição. Incorporação das curvas de crescimento da Organização Mundial da Saúde de 2006 e 2007 no Sisvan. Available at: <http://www.saude.gov.br/nutrição>. Accessed on: Feb 10. 2014.

10. Freedman DS, Serdula MK, Srinivasan SR, Berenson GS. Relation of circumferences and skinfold thicknesses to lipid and insulin concentrations in children and adolescents: the Bogalusa Heart Study. Am J Clin Nutr. 1999;69(2):308-17.

11. Fryar $\mathrm{CD}, \mathrm{Gu} \mathrm{Q}$, Ogden $\mathrm{CL}$. Anthropometric reference data for children and adults: United States, 2007-2010. Vital Health Stat 11. 2012;(252):1-48.

12. National High Blood Pressure Education Program Working Group on High Blood Pressure in Children and Adolescents. The fourth report on the diagnosis, evaluation, and treatment of high blood pressure in children and adolescents. Pediatrics. 2004;114(2 Suppl 4th Report):555-76.

13. FriedewaldWT, Levy RI, Fredrickson DS. Estimation of the concentration of low-density lipoprotein cholesterol in plasma, without use of the preparative ultracentrifuge. Clin Chem. 1972;18(6):499502.

14. Matthews DR, Hosker JP, Rudenski AS, Naylor BA, Treacher DF, Turner RC. Homeostasis model assessment: insulin resistance and beta-cell function from fasting plasma glucose and insulin concentrations in man. Diabetologia. 1985;28(7):412-9.

15. Agirbasli M, Agaoglu NB, Ergonul O, Yagmur I, Aydogar H, Oneri $\mathrm{T}$, et al. Comparison of anthropometric indices in predicting metabolic syndrome components in children. Metab Syndr Relat Disord. $2011 ; 9(6): 453-9$.

16. Okorodudu DO, Jumean MF, Montori VM, Romero-Corral A, Somers VK, Erwin PJ, et al. Diagnostic performance of body mass index to identify obesity as defined by body adiposity: a systematic review and meta-analysis. Int J Obes (Lond). 2010;34(5):791-9.

17. Savva SC, Tornaritis M, Savva ME, Kourides $Y$, Panagi A, Silikiotou $\mathrm{N}$, et al. Waist circumference and waist-to-height ratio 
are better predictors of cardiovascular disease risk factors in children than body mass index. Int $\mathrm{J}$ Obes Relat Metab Disord. 2000;24(11):1453-8.

18. Goran MI, Gower BA, Treuth M, Nagy TR. Prediction of intraabdominal and subcutaneous abdominal adipose tissue in healthy pre-pubertal children. Int J Obes Relat Metab Disord. 1998;22(6):549-58

19. Saelens BE, Seeley RJ, van Schaick K, Donnelly LF, O'Brien KJ. Visceral abdominal fat is correlated with whole-body fat and physical activity among 8-y-old children at risk of obesity. Am J Clin Nutr. 2007;85(1):46-53.

20. Dencker M, Thorsson O, Lindén C, Wollmer P, Andersen LB, Karlsson MK. BMI and objectively measured body fat and body fat distribution in prepubertal children. Clin Physiol Funct Imaging. 2007;27(1):12-6

21. Chiara VL, Da Silva HGV, Barros ME, Rêgo AL, Ferreira AL, Pitasi $\mathrm{BA}$, et al. Correlação e concordância entre indicadores de obesidade central e índice de massa corporal em adolescentes. Rev Bras Epidemiol. 2009;12(3):368-77.

22. Bigornia SJ, LaValley MP, Benfield LL, Ness AR, Newby PK. Relationships between direct and indirect measures of central and total adiposity in children: what are we measuring? Obesity (Silver Spring). 2013;21(10):2055-62.

23. Alvarez MM, Vieira ACR, Sichieri R, Veiga GV. Associação das medidas antropométricas de localização de gordura central com os componentes da síndrome metabólica em uma amostra probabilística de adolescentes de escolas públicas. Arq Bras Endocrinol Metab. 2008;52(4):649-57.

24. Moser DC, Milano GE, Brito LMS, Titski ACK, Leite N. Pressão arterial elevada, excesso de peso e obesidade abdominal em crianças e adolescentes. Rev Educação Física. 2011;22(4):591-600.

25. Ho TF. Cardiovascular risks associated with obesity in children and adolescents. Ann Acad Med Singapore. 2009;38(1):48-9.

26. Moreira NF, Muraro AP, Santos FSB, Gonçalves-Silva RMV, Sichieri R, Ferreira MG. Obesidade: principal fator de risco para hipertensão arterial sistêmica em adolescentes brasileiros participantes de um estudo de coorte. Arq Bras Endocrinol Metab. 2013;57(7):520-6.

27. Lee S, Bacha F, Gungor N, Arslanian SA. Waist circumference is an independent predictor of insulin resistance in black and white youths. J Pediatr. 2006;148(2):188-94.

28. Camhi SM, Kuo J, Young DR. Identifying adolescent metabolic syndrome using body mass index and waist circumference. Prev Chronic Dis. 2008:5(4):A115.

29. Bacha F, Saad R, Gungor N, Arslanian SA. Identifying adolescent metabolic syndrome using body mass index and waist circumference. Prev Chronic Dis. 2008;5(4):A115.

30. Blüher S, Molz E, Wiegand S, Otto KP, Sergeyev E, Tuschy $S$, et al. Body mass index, waist circumference, and waist-to-height ratio as predictors of cardiometabolic risk in childhood obesity depending on pubertal development. J Clin Endocrinol Metab. 2013;98(8):3384-93.
31. Haney EM, Huffman LH, Bougatsos C, Freeman M, Steiner RD, Nelson HD. Screening and treatment for lipid disorders in children and adolescents: systematic evidence review for the US Preventive Services Task Force. Pediatrics. 2007;120(1):e189-214.

32. Lapice E, Maione S, Patti L, Cipriano P, Rivellese AA, Riccardi G, et al. Abdominal adiposity is associated with elevated $\mathrm{C}$-reactive protein independent of BMI in healthy nonobese people. Diabetes Care. 2009;32(9):1734-6.

33. Gillum RF. Association of serum C-reactive protein and indices of body fat distribution and overweight in Mexican American children. J Natl Med Assoc. 2003;95(7):545-52.

34. Lambert M, Delvin EE, Paradis G, O'Loughlin J, Hanley JA, Levy E. C-reactive protein and features of the metabolic syndrome in a population-based sample of children and adolescents. Clin Chem. 2004;50(10):1762-8.

35. Galcheva SV, lotova VM, YotovYT, Bernasconi S, Street ME. Circulating proinflammatory peptides related to abdominal adiposity and cardiometabolic risk factors in healthy prepubertal children. Eur J Endocrinol. 2011;164(4):553-8.

36. Wärnberg J, Nova E, Moreno LA, Romeo J, Mesana MI, et al.; AVENA Study Group. Inflammatory proteins are related to total and abdominal adiposity in a healthy adolescent population: the AVENA Study. Am J Clin Nutr. 2006;84(3):505-12.

37. Galcheva SV, lotova VM, YotovYT, Bernasconi S, Street ME. Circulating proinflammatory peptides related to abdominal adiposity and cardiometabolic risk factors in healthy prepubertal children. Eur J Endocrinol. 2011;164(4):553-8.

38. Zhang X, Wang L, Chen B. Recombinant HDL (Milano) protects endotoxin-challenged rat from multiple organ injury and dysfunction. Biol Chem. 2015;396(1):53-60.

39. Balas-Nakash M, Perichart-Pereira O, Benítez-Arciniega A, Tolentino-Dolores M, Mier-Cabrera J, Vadillo-Ortega F. Asociación entre adiposidad, inflamación y factores de riesgo cardiovascular em um grupo de escolares mexicanos. Gaceta Médica de México. 2013;149:196-203.

40. Van Harmelen V, Reynisdottir S, Eriksson P, Thörne A, Hoffstedt $J$, Lönnqvist $F$, et al. Leptin secretion from subcutaneous and visceral adipose tissue in women. Diabetes. 1998;47(6):913-7.

41. Kishida K, Kim KK, Funahashi T, Matsuzawa Y, Kang HC, Shimomura I. Relationships between circulating adiponectin levels and fat distribution in obese subjects. J Atheroscler Thromb. 2011;18(7):592-5.

42. Reinehr T, Roth $\mathrm{C}$, Menke T, Andler W. Adiponectin before and after weight loss in obese children. J Clin Endocrinol Metab. 2004;89(8):3790-4.

43. Miller RA, Chu Q, Le Lay J, Scherer PE, Ahima RS, Kaestner KH, et al. Adiponectin suppresses gluconeogenic gene expression in mouse hepatocytes independent of LKB1-AMPK signaling. J Clin Invest. 2011;121(6):2518-28.

44. Kochan Z, Karbowska J. [Resistine - a new hormone secreted by adipose tissue (adipose tissue in insulin resistance)]. Przegl Lek. 2003;60(1):40-2 